broth, even when 0.8 per cent formalin was used. The loss in antigenicity during preparation of the toxoid (measured by flocculation) was about half that usually found.

Guinea pigs immunized with a single dose of $1 / 40$ c.c. of the new toxoid showed after a month a mean serum titre of 80 laboratory units. This compares with an average of 20 units obtained by immunization with 0.5 c.c. of ordinary toxoid. In practice, $0.5-1$ unit of circulating antitoxin adequately protects a bovine against natural botulism (lamsiekte).

Onderstepoort Laboratories.

A. PoLson

Cyclic Variations of the Submicroscopic Structure of the Cortical Layer of Fertilized and Parthenogenetic Sea Urchin Eggs

THE cortical layer of the unfertilized egg of Psammechinus miliaris exhibits a remarkable positive birefringence (with respect to the radial axis) which has been interpreted as meaning that the cortical layer is built up of radially arranged lipid molecules ${ }^{2}, 2$. The birefringence disappears at fertilization and reappears during the anaphase of the first mitosis ${ }^{3}$. This means that the cortical layer undergoes rhythmic variations of its submicrosepic structure. We have investigated the cycle of such structural variations in relation to the phases of mitosis and to the modifications of permeability occurring during the early stages of development, in both fertilized and parthenogenetic eggs.

Birefringence totally disappears immediately after fertilization as ell fisappears immediately after reappears, in both cases, about 10-15 min t. It $\left(t^{\circ}=15^{\circ}-18^{\circ}\right)$ bout cases, about $10-15$ min. later ( Between 15-20 min. and 50 min. after activation, the cortical layer is isotropic. It shows again a beautiful and very brilliant positive birefringence with polarization cross, from $50 \mathrm{~min}$. to $1 \mathrm{hr}$. after activation, corthe fertilized eggs and to maximum expansion of the monaster in the parthenogenetic eggs.

Later on the pirefringenetic egs. Later on, the birefringence disappears when the genetic eggs is undergoing reduction. At about $1 \mathrm{hr}$. 30 min., the cortical layer again shows birefringence corresponding to the ana-telophase of the second division and to the expansion of the second monaster cycle.

The question arises whether the rhythm of the structural variations of the cortical layer is dependent upon the spindle cycle. Colchicine treatment, which inhibits spindle formation as well as the appearance of the spermaster in fertilized eggs and of the monaster in parthenogenesis, does not alter the rhythm of birefringence. Thus the birefringence cycle, although entirely independent of them.

Two types of plasmolysis have been described in the fertilized and parthenogenetic eggs, following treatment with hypertonic sea water. indicating different physical conditions of the cortical layer: a 'smooth' and an 'angular' plasmolysis'. In the first case the egg contracts, preserving its spherical form; whereas in the second it acquires a wrinkled surface. We found that smooth plasmolysis ours when the cortical layer shows birefringence (both in normal and in colchicine treated eggs); angular plasmolysis corresponds exactly to the phases of absence of birefringence.

A discussion of these findings will be published later in a more extensive paper.

Zoological Station,

Naples.

Department of Genetics,

University of Naples.

June 30.

' Runnström, J., Monné, L., and Broman, L., Ark. Zool. (Stockholm), $35, \mathrm{~A}$, No. 3 (1943)

2 Monroy, A., and Monroy Oddo A., Boll. Soc. Ital. Biol. Sper., 20, 237 (1945). Pubbl. Staz. Zool. Napoli, 20, 46 (1946).

' Runnström, J., Protopl., 4, 388 (1928).

\section{A Decaploid Strain of Artemia salina}

ON March 8, 1946, Dr. M. Levy, a chemist in the Palestine Potash Company at the north end of the Dead Sea, handed us a number of living specimens of the brine shrimp (Artemia salina) which he had found in abundance in the salt-washing pans of the potash works. In these pans the salt residue of Dead Sea water is washed out by admitting fresh water from the Jordan. This water gradually increases in salinity, but the various ions are represented in this solution in proportions differing from those of Dead Sea water. Especially, the magnesium concentration is relatively much lower than in the Dead Sea. At the time of collecting, the specific gravity of the water measured at $20^{\circ} \mathrm{C}$. was $1 \cdot 173$ (potassium chloride $4 \cdot 2$, sodium chloride $22 \cdot 0$, calcium chloride and magnesium chloride $37 \cdot 2 \mathrm{gm} . / \mathrm{I}$; ; total of chlorine, $165 \mathrm{gm} . / 1$.).

It must be assumed that we have here an invasion of Artemia into a relatively new artificially produced biotope. The specific gravity of the water in this new locality is higher than that of the most concentrated solutions in which Gross ${ }^{1}$ was able to keep his brine shrimp. On transferring the animals into Dead Sea water, they were found to survive no longer than six hours. Artemia is known to occur in Palestine at a distance of some $120 \mathrm{~km}$., in the marine salt pans of Atlit, near Haifa.

Some of the animals, which were exclusively parthenogenetic females, were flxed in Carnoy's fluid. The chromosome number was determined as usual, in metaphase plates of the first oocytes. Of five specimens so far examined, one showed 107, two 108 and two 109 tetrads. Since the basic haploid number of Artemia salina is known to be 21 , the present race must be considered as decaploid with a slight augmentation of the number of 105 tetrads. This deviation from the expected number may be interpreted in two possible ways. On one hand, there may be two to four supernumerary chromosomes fluctuating In the population. On the other hand, the deviation from the number of 105 tetrads may be due to failure of prophase pairing in homologues. We might be dealing with 103 tetrads and 4 dyads, or with 102 tetrads and 6 dyads, or with 101 tetrads and 8 dyads. It is not impossible that polysomy and failure of pairing may be jointly responsible for the abnormal numbers observed. be noted that wherever details could be distinguished, the metaphase figures presented the aspect of toud be distinguished, the metaphase ated, several had been fixed immediately after their arrival in the laboratory, others had been kept up to six weeks in various concentrations of Mediterranean sea water.

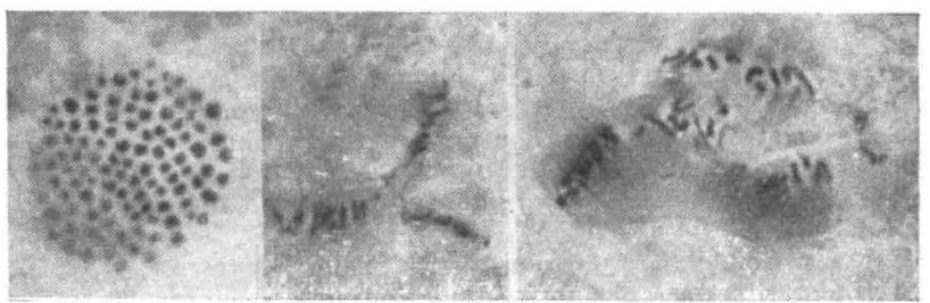

1

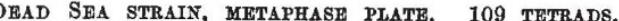
HEIDENHAIN's HX. $\times$ c. 1250 ULTIPOLAR FIRST CLEAVAGE FIGURE PARTHENOGENETIO EGG, DEAD SEA
N ACCORDANCE WITH THE THREE OENTRES PRESENT, THE CHROMOSOMKS

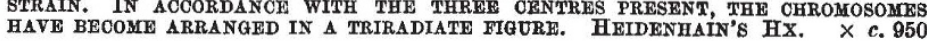

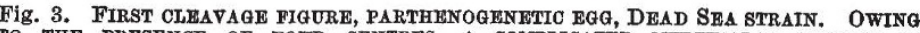
PRESENCE OF FOUR CENTRES, A COMPLIOATED MULTIPOLAR SPINDLE IS
THE LEFT-HAND PART OF WHICH IS SEEN IN SIDE VIEW, THE RIGHTAND PART IN EQUATORIAL vIEW. HEIDENHAIN's HX. $\times$ c. 1100 